\title{
The General Sinus
}

\section{Mostafa Derraz*}

Department of Electrical Engineering, Abdelmalik Essaadi Université, Morocco

\begin{abstract}
In this paper, we will generalize the Sinus function (than the all Trigonometry function), the general Sinus is defined by two parameter $\operatorname{Sin}(x, y)$, which it's be able to use in n-gon not necessary in rectangle. We will apply the general trigonometry function in n-gon, in order to determine the all intrinsic properties of n-gon, using a minimum and reasonable amount of data and no condition apply in n-gon nature, based in construability of polygon we determine it's in this mount $n-2$ segments and $n$ angles. Finally we will prove this formula is the must generalized in Euclidian geometry.
\end{abstract}

Keywords: Trigonometry function; Geometry; Polygons; Sinus

\section{Historical Comments}

To present the History in a correct way, we will devise it in two parts. In the first one, we will expose a short history of the trigonometrically functions and law of Sinus, and in the second one will be reserved to the history of polygons and the works of some scientist who tried to end a general formula in the geometry polygon.

\section{Trigonometry function and law of sinus}

Let's start by the lexicon of the word trigonometry, it's comes from the Greek "Trine" (triangle) and "Metron" (measure). The word "Sinus" comes from a confusion of translation from Arabic to Latin. In Arabic, "gabr" means both the opening at the chest of a garment and the half string double angle (our current sinus). When Latinists mathematicians have tried to translate this term, they have translated it as Sinus which means "fold of the toga" in Latin. The "Co sinus" of an angle is the complementary to the sinus of this angle, hence the term "Co sinus" $[1,2]$.

Let's back in the first use. In 2000 years before our era, the Babylonians applied geometry only in astronomy, using tables of calculations that divide a circle made form $360^{\circ}$ into angles of $60^{\circ}$ [3]. Moving on to the seventh century, using a half rope, the old Indian Aryabhata first gave us the first tables of the sinus of an angle, then addressed. The trigonometry into a circle [4]. Later on, in the ninth century Mohammed al Battani introduced a table of tangent of an angle [5]. Moving on to the thirteenth century, the Persian al Tusi, separated geometry from astronomy [6]. Then in the tenth century astronomer and mathematician Johann Miller, introduced the systematic use of the term sinus. As a result, trigonometry developed as an independent branch of mathematics [7]. A century later, the French Francois Vieta, counsellor of Henri IV, will evolve trigonometry, to give it the character we know today. Trigonometry became a wide range of applications in a variety of sciences, physical acoustics, optics, electronics, statistics, economics, biology, chemistry, medicine, meteorology, geodesy, geography, cartography, cryptography [8].

One of the important formula in the Euclidean geometry is the law of sinus [9]. Finally, in 2011 Russell generalized the law of sinus and applied it to a simplex space of any dimension with constant (Gaussian curvature) [10]. Let us work up to that initially in two dimension simplex (line segment) with content (length) $\mathrm{S}$ in space of constant (Gaussian curvature) K as:

$$
g \sin S-K \frac{s^{3}}{3 !}+K \frac{s^{5}}{5 !}-K \frac{s^{7}}{7 !}+\ldots
$$

\section{Geometry of the polygon}

Gauss had discovered that besides the regular polygons of $2 \mathrm{n} .3$, $2 \mathrm{n} .4,2 \mathrm{n} .5$ and $2 \mathrm{n} .15$ sides, there were a number of other constructible polygons, including the 17-gon. Gauss secured priority to his discovery by publishing an announcement on June 1, 1796, which appeared in the "Intelligenez Blalt Derallge-meinen Literaturzellung", the first and only time he published in a journal of advance notices. In his short note he wrote that "This discovery is really only a corollary of a theory with greater content, which is not complete yet, but which will be published as soon as it is complete" $[11,12]$.

The full meaning of Gauss pronouncement came in 1801 with the publication of his monumental Disquisitions arithmetic [13]. Its final two sections (articles 365 and 366) discuss the issue of polygon constructability. Recasting the problem in terms of constructing the $\mathrm{n}$ vertices of the polygon on a given circle, Gauss stated his result as follows: In general in order to divide the circle geometrically into $\mathrm{n}$ parts, $\mathrm{n}$ must be 2 or a higher power of 2 or a prime number of the form $2^{\mathrm{m}}+1$ or the product of several prime number of this form or the product one or several such primes into 2 or a higher power of 2 .

This sufficiency of the condition follows readily forms Gauss analysis.

This necessity, however, is not obvious and Gauss never published a proof of this assertion. The first proof is credited to Wantzel [14].

Primes of the form $2^{\mathrm{m}}+1$, and therefore necessarily of the form $\mathrm{F}_{\mathrm{k}}=2^{2 \mathrm{k}}$ are the Fermat primes and he knew that Euler had shown $\mathrm{F}_{5}$ to be composite. Even today no other Fermat primes have been found, although the smallest unsettled cases are $\mathrm{F}_{22}, \mathrm{~F}_{24}$ and $\mathrm{F}_{26}$ (The primarily status of Fermat numbers as of 1983 can be found in Keller [15] and a shorter but more recent table is included in Young and Buell [16]).

Beyond the brilliant theoretical breakthrough of Gauss there is still an intriguing puzzle:

*Corresponding author: Derraz M, Department of Electrical Engineering, Abdelmalik Essaadi Université, Morocco, Tel: +212665104683; E-mail: Derraz90@gmail.com

Received January 05, 2017; Accepted May 24, 2017; Published May 31, 2017

Citation: Derraz M (2017) The General Sinus. Int J Swarm Intel Evol Comput 6 155. doi: 10.4172/2090-4908.1000155

Copyright: (c) 2017 Derraz M. This is an open-access article distributed under the terms of the Creative Commons Attribution License, which permits unrestricted use, distribution, and reproduction in any medium, provided the original author and source are credited. 
How can one devise a sequence of steps with straightedge and compass which constructs a regular n-gon? Gauss expressed interest in this problem, although he did not offer explicit geometric constructions. Throughout the last century, and even into present times, numerous constructions have been contrived for the 17-gon [11,17]. Richelots's constructions of the 275-gon required a total of 194 pages, published in four parts in "Grelles" journal in 1832. A professor "Hermes" laboured ten years on the construction and associated algebra of the 65537gon. The work filled a trunk which was donated to the Mathematical Institute at Gottingen.

Nearly a century later it remains stored in an attic there, in all likelihood having never been read. Fallowing to Gauss, we found that "Roark" worked on regular polygons and found a series of equations that defined by segment, radius of interior circle, radius of exterior circle [18]. And in 1979 "Court" found out an equation gathering all the properties of a polygon vertex. [19]

Another scientist worked on polygon is "\{Ptolemy\}": "Ptolemy's Theorem" is a relation among these lengths in a cyclic quadrilateral. In Euclidean geometry Ptolemy's Theorem is a relation between the four sides and two diagonals of a cyclic quadrilateral. "Ptolemy" used the theorem as an aid to creating his table of chords, a trigonometric table that he applied to astronomy. [20]

\section{Results and Discussion}

In fact this part, we will discuss two themes. In the first one we will generalize the Trigonometrically Function (based on the law of sinus) [9] in the second one we will use the latest results (General trigonometrically function) to find the general formula .This formula can determinate all the propriety of a polygon based on the minimal amount of data, and we will prove that it's the most generalized.

\section{The general Sinus}

In this paragraph we will discuss the general trigonometrically function based on the projections of a point on a line and the law of sinus. We know that the principal trigonometrically function is the sinus function. So that what we are going to start with:

If we observe the definition (formula) of the sinus $\left(\sin \left(\alpha_{1}\right)=X=\frac{A_{1} A_{3}}{A_{1} A_{3}}\right)$, we found that the formula calculate the opposite of the proportion distance $\left(\overline{\mathrm{A}_{1} \mathrm{~A}_{3}}\right)$ between the vertices (point $A_{2}$ ) of the angle (angle $\alpha_{1}$ ) and a point included in it (point $A_{1}$ ) and the distance $\left(\overline{\mathrm{A}_{1} \mathrm{~A}_{3}}\right)$ between the point (point $\mathrm{A}_{1}$ ) and it's verticals projection on the other segment (point $A_{3}$ ) of the studied (angle $\alpha_{1}$ ) (Figure 1).

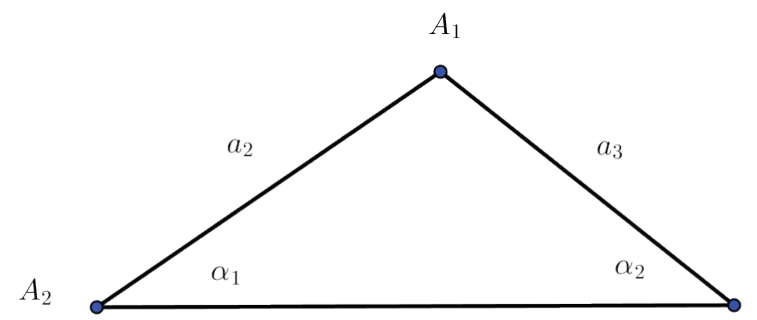

$A_{3}$

$a_{1}$

Figure 1: The triangle.

\section{Remark 1}

We notice that the formula (actual) of sinus is just a special case not a general formula, because it's defined by the vertical projection, which is just a special case of the projection.

If we joined these points we will get a triangle (exactly rectangle) $A_{1} A_{2} A_{3}$. So the use of the sinus (actual) is limited in rectangles, as result it can calculate the segment $\overline{\mathrm{A}_{2} \mathrm{~A}_{3}}$ in function of another segment $\overline{\mathrm{A}_{2} \mathrm{~A}_{3}}$ and the studied angle $\alpha_{1}$.

$$
\overline{\mathrm{A}_{1} \mathrm{~A}_{3}}=\sin \left(\alpha_{1}\right) \cdot \overline{\mathrm{A}_{2} \mathrm{~A}_{3}}
$$

So if we want to calculate the distance $\overline{\mathrm{A}_{1} \mathrm{~A}_{3}}$ in a triangle which is not necessarily rectangle (the general use of sinus), we must generalize the function sinus, it means to generalize the projection (not necessarily vertical projection), so we can redefine the formula of the sinus with another variable (the projection angle), in fact the (actual) sinus is defined by two variables not one, because it defined by vertical projection (in fact we must see projection fallowing angle $\frac{\pi}{2}$ ), it means the (actual) sinus defined by two angles , the first one is the studied angle and the second one the particulaire projection angle $\frac{\pi}{2}$.

Finally the general Sinus must be defined by two angles:

1. The studied angle.

2. The projection angle.

\section{Remark 2}

According the conjunction in definition between sinus and Co sinus, so we will use the same analyze to generalize the Co sinus, then the function Tangent.

We announced in previous paragraph that the key to generalize the sinus is to find the function which is able to calculate the $\overline{\mathrm{A}_{1} \mathrm{~A}_{3}}$

in a triangle (not necessarily rectangle).

These propose is served, if we use the law of sinus in this triangle. According to this law, we can calculate this segment, as a result we will find the general formula of the sinus.

The generalizing of the trigonometrically functions, necessity to create a new function to calculate the projection angle, which is defined by the two segment $\overline{\mathrm{A}_{2} \mathrm{~A}_{3}}$

and $\overline{\mathrm{A}_{2} \mathrm{~A}_{3}}$

one angle (studied angle $\alpha_{1}$ ).

We named the new function (direction), it means in Latin (direction) [21].

\section{Theorem 1}

The general sinus: In the triangle $\mathrm{A}_{1} \mathrm{~A}_{2} \mathrm{~A}_{3}$ (not necessarily rectangle), where:

$\alpha_{1}=A_{1} A_{2} A_{3}$

$\alpha_{2}=A_{1} A_{2} A_{3}$ Projection angle (Figure 2).

The condition to form a triangle: $\alpha_{2}+\alpha_{1} \neq \mathrm{n} \pi, \mathrm{n} \in \mathrm{N}$

The general sinus:

$$
\sin \left(\alpha_{1}, \alpha_{2}\right)=\frac{\sin \left(\alpha_{1}\right)}{\sin \left(\alpha_{1}+\alpha_{2}\right)}
$$

\section{Theorem2}

The general trigonometrically function: In the triangle $A_{1} A_{2} A_{3}$ 


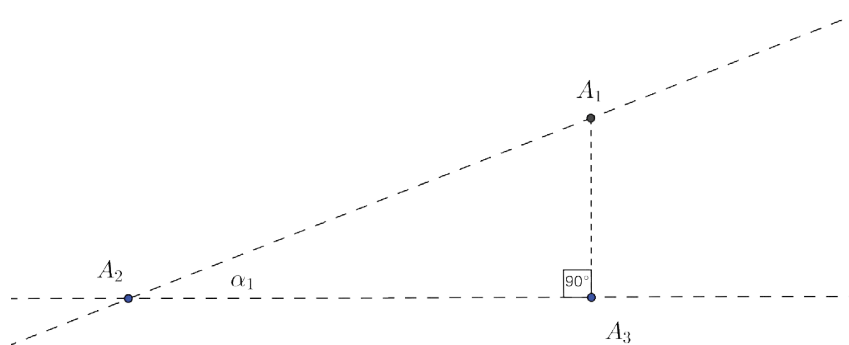

Figure 2: The vertical projection.

(not necessarily rectangle), where:

$\alpha_{1}=A_{1} A_{2} A_{3}$.

$\alpha_{2}=A_{1} A_{2} A_{3}$ Projection angle (Figure 2).

The condition to form a triangle: $\alpha 1 \alpha 2 \neq n \pi, n \in N$

The general formula of Trigonometrical Function:

$$
\begin{aligned}
& \sin \left(\alpha_{1}, \alpha_{2}\right)=\frac{\sin \left(\alpha_{1}\right)}{\sin \left(\alpha_{1}+\alpha_{2}\right)} \\
& \cos \left(\alpha_{1}, \alpha_{2}\right)=\frac{\sin \left(\alpha_{2}\right)}{\sin \left(\alpha_{1}+\alpha_{2}\right)} \\
& \tan \left(\alpha_{1}, \alpha_{2}\right)=\frac{\sin \left(\alpha_{1}\right)}{\sin \left(\alpha_{2}\right)}
\end{aligned}
$$

\section{Theorem 3}

The function direction: In the triangle $\mathrm{A}_{1} \mathrm{~A}_{2} \mathrm{~A}_{3}$ (not necessarily rectangle), where:

$\alpha_{1}=A_{1} A_{2} A_{3}$

$\alpha_{2}=A_{1} A_{2} A_{3}$ Projection angle (Figure 2).

The condition to form a triangle: $\alpha 1 \alpha 2 \neq n \pi$, nòN

The function direction represent the projection angle $\alpha_{2}$ defined by the angle $\alpha_{1}$ and its segments $\mathrm{A}_{1} \mathrm{~A}_{2}$

$$
\text { and } \overline{A_{1} A_{3}}
$$

\section{Definition 1}

Trigonometrically function value's e and general unit circle: Fallowing the theorem (1) and theorem (2) we will build the value's table of usual angles in case the general Trigonometrical Function (Table 1).

We create the new conjuration (the value circle) to reduce and present the results of the last table like the value circle of the actual sinus, with a difference, this conjuration is defined by two circles not one, the first represents the studied angle (the same in the actual sinus) and the second represents the projection angle (Figures 3 and 4).

The value of start (0) in the second circle is the studied angle of the first circle. To use this conjuration we must fixe (first) the studied angle in the first circle and we will get the value of start (0) in the second circle then we fix the projection angle in second circle (see an example how to

\begin{tabular}{|c|c|c|c|c|c|}
\hline & 0 & $\frac{\mathrm{II}}{6}$ & $\frac{\text { II }}{3}$ & $\frac{\text { II }}{3}$ & $\frac{\text { II }}{2}$ \\
\hline 0 & 1 & 1 & 1 & 1 & 1 \\
\hline$\frac{\mathrm{II}}{6}$ & 0 & $\sqrt{3}$ & $\sqrt{3}-1$ & $\frac{2 \sqrt{3}}{3}$ & $\frac{2 \sqrt{3}}{3}$ \\
\hline$\frac{\mathrm{II}}{4}$ & 0 & $\frac{\sqrt{6}-\sqrt{2}}{2}$ & $\frac{\sqrt{2}}{2}$ & $\frac{3 \sqrt{2}-\sqrt{6}}{2}$ & $\sqrt{2}$ \\
\hline$\frac{1}{2}$ & 0 & $\frac{1}{2}$ & 3 & 1 & 2 \\
\hline$\frac{\sqrt{3}}{3}$ & 0 & $\frac{\sqrt{3}}{3}$ & 1 & $\sqrt{3}$ & $\infty$ \\
\hline
\end{tabular}
use it in the paragraph: Analogy between the actual Trigonometrically Function and general form) (Figures 5-7).

\section{The graphic presentation}

The graph of Sinus is 3D view is a surface in space reference by

Table 1: Trigonometrically function value's.

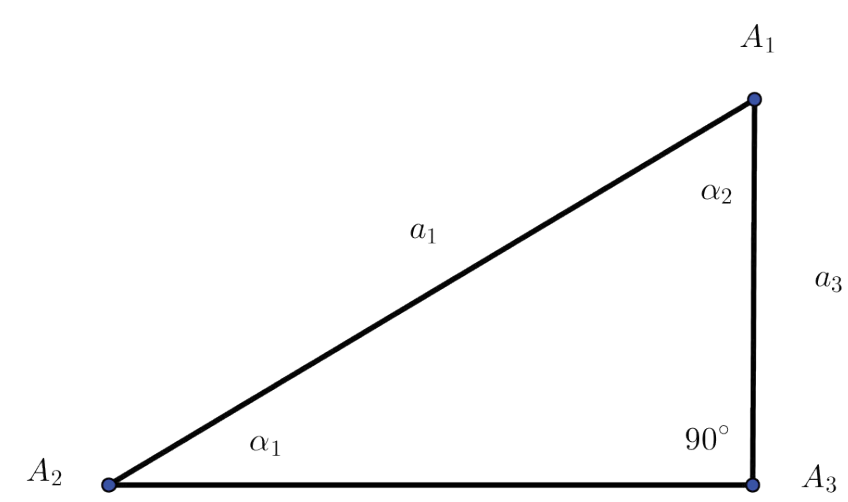

$a_{2}$

Figure 3: The rectangle.

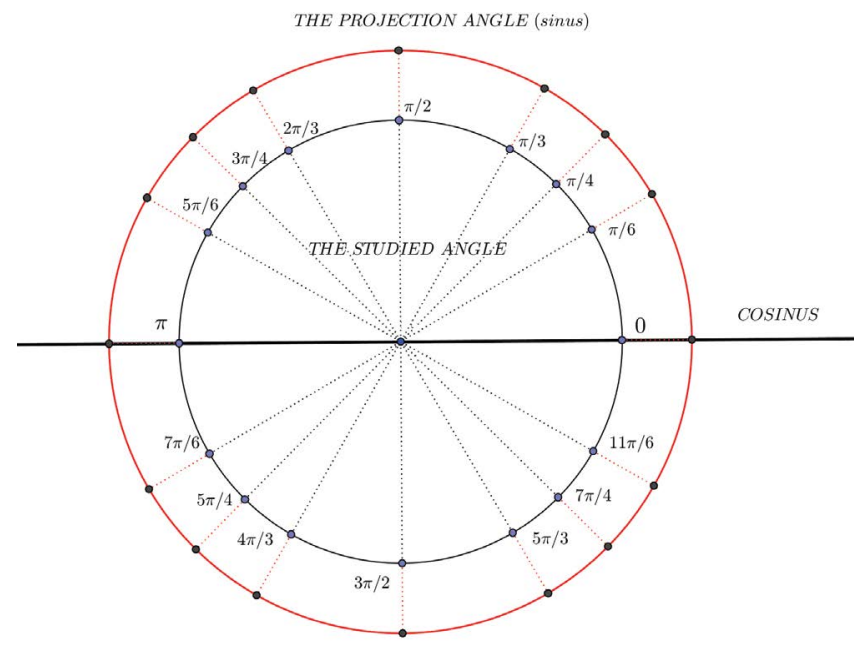

Figure 4: The value circle presentation. 


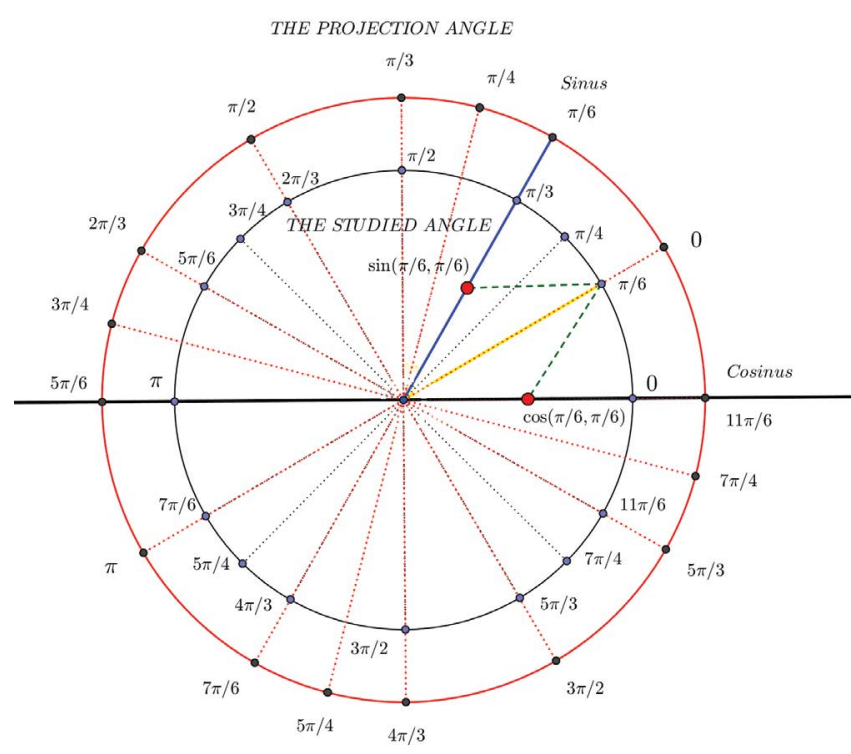

Figure 5: The value circle example 1.

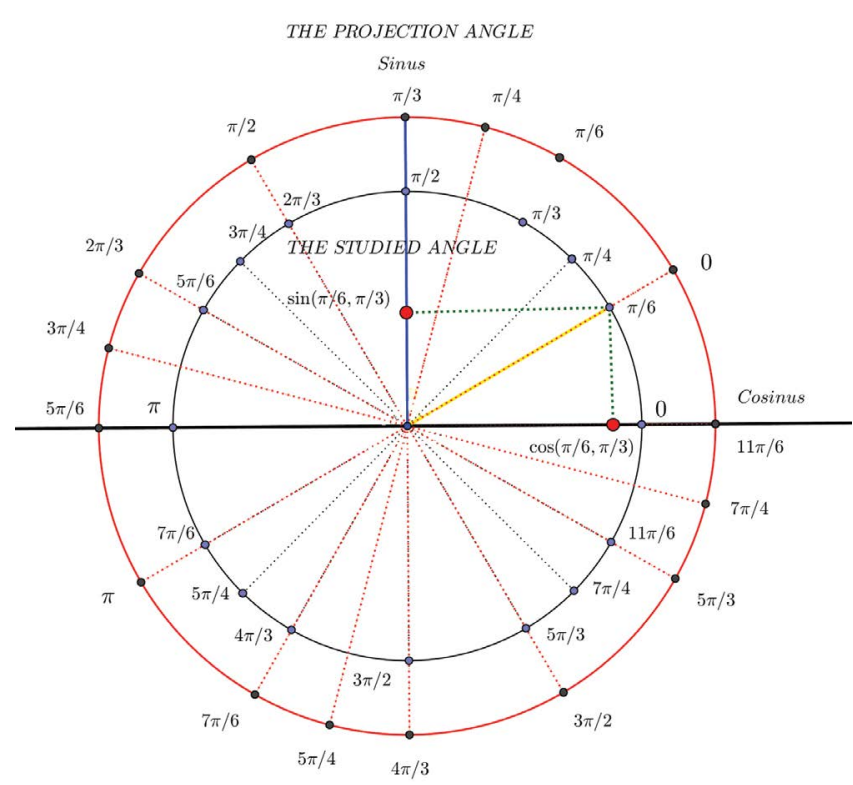

Figure 6: The value circle example 2.

two variables (two angles) and other one in amplitude (segment), also Direction function (Figures 8 and 9).

\section{Proof 1}

This proof we will be based on the previous discussion, we reduce the discussion into the following:

The key to generalize the sinus, is to find a function which can calculate the $\mathrm{A}_{1} \mathrm{~A}_{3}$ in a triangle (not necessarily rectangle).

This purpose was resolved, if we used the law of sinus in this triangle.
According to this law, we can calculate this segment. Consequently we will find the general formula of the sinus.

$$
\begin{aligned}
& \mathrm{a}_{3}=\frac{\sin \left(\alpha_{1}\right)}{\sin \left(\alpha_{1}+\alpha_{2}\right)} \alpha_{1} \\
& \mathrm{a}_{2}=\frac{\sin \left(\alpha_{2}\right)}{\sin \left(\alpha_{1}+\alpha_{2}\right)} \alpha_{1}
\end{aligned}
$$$$
\text { Let's comeback to Sinus law (Figure 2): }
$$

We find that the function in equation (7) calculate the Sinus side of the angle $\alpha_{1}$ and the function in equation (8) calculate the adjunct segment of the angle $\alpha_{1}$, so this function has the same purpose of the (actual) function sinus and Co sinus with a simple different, these functions are used in the general form of a triangle (not necessarily rectangle), so we can deduct that those functions are the general form of the actual sinus and Co sinus, also they general form is available in any triangle (see detail in the next paragraph: Analogy between actual function and general form )

In what comes next, we based on the law of sinus and we will create a new concept, function direction, as we announced in previous discussion, this function presents the angle of projection $\left(\alpha_{2}\right)$. To create the formula of direction, we will consider a triangle with the parameters.

Angle $\left(A_{3} A_{2} A_{1}: \alpha_{1}\right)$ : Two segment of studied angle $A_{1} A_{2}: \alpha_{2}$ and $A_{1} A_{3}: \alpha_{1}$ and we want to find the angle $\alpha_{2}$, which is the angle of projection.

Back to the formula of the Sinus law (equation 7 and equation 8), we will resolve this equation where $\alpha_{2}$ is variable and $\left(\alpha_{1}, a_{1}\right.$ and $\left.a_{2}\right)$ are the parameters. We find:

$$
\begin{aligned}
& \alpha_{2}=\arctan \left(\frac{a_{1}}{a_{2} \sin \left(\alpha_{1}\right)}-\operatorname{cotan}\left(\alpha_{1}\right)^{-1}\right) \\
& \text { We note } \\
& \text { Direction } \left.\left(a_{1} a_{2} a_{1}\right)=\arctan \left(\frac{a_{1}}{a_{2} \sin \left(\alpha_{1}\right)}-\operatorname{cotan}\left(\alpha_{1}\right)^{-1}\right)\right)
\end{aligned}
$$

\section{Analogy between the actual trigonometrically function and general form}

In this part we will compare between the actual trigonometrically function and general form.

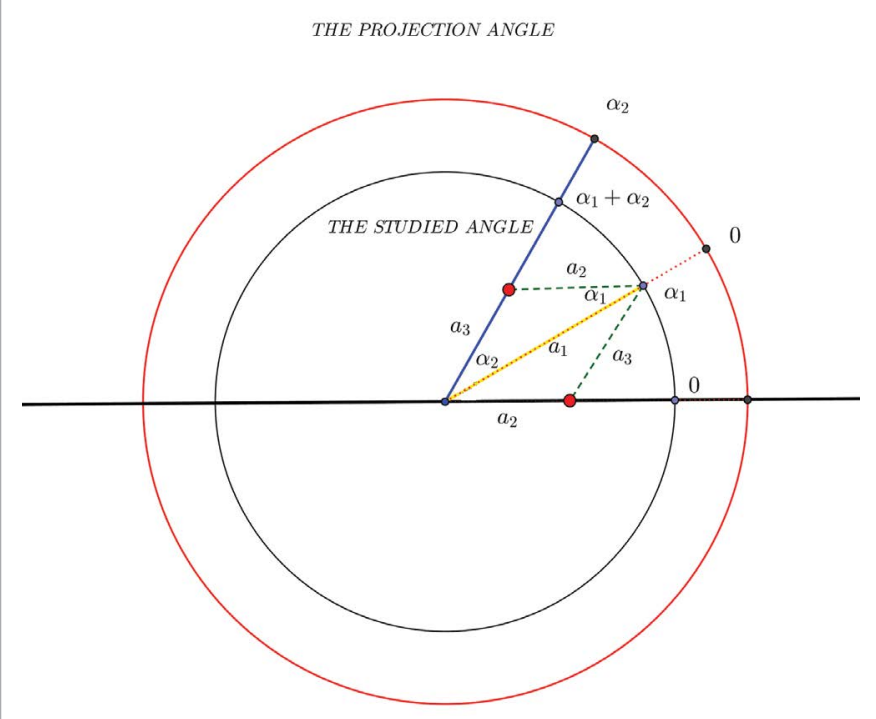

Figure 7: The value circle proof. 

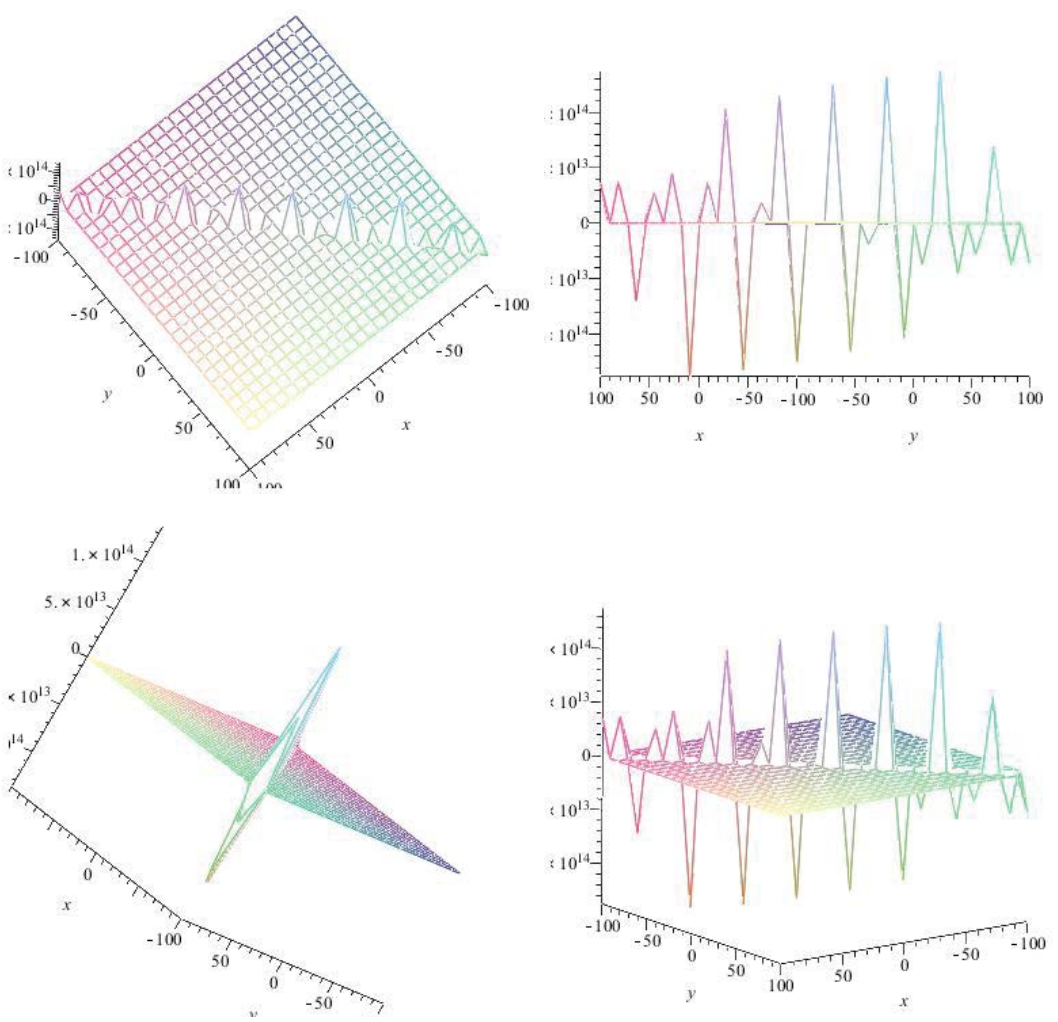

Figure 8: The sinus graphic presentation.
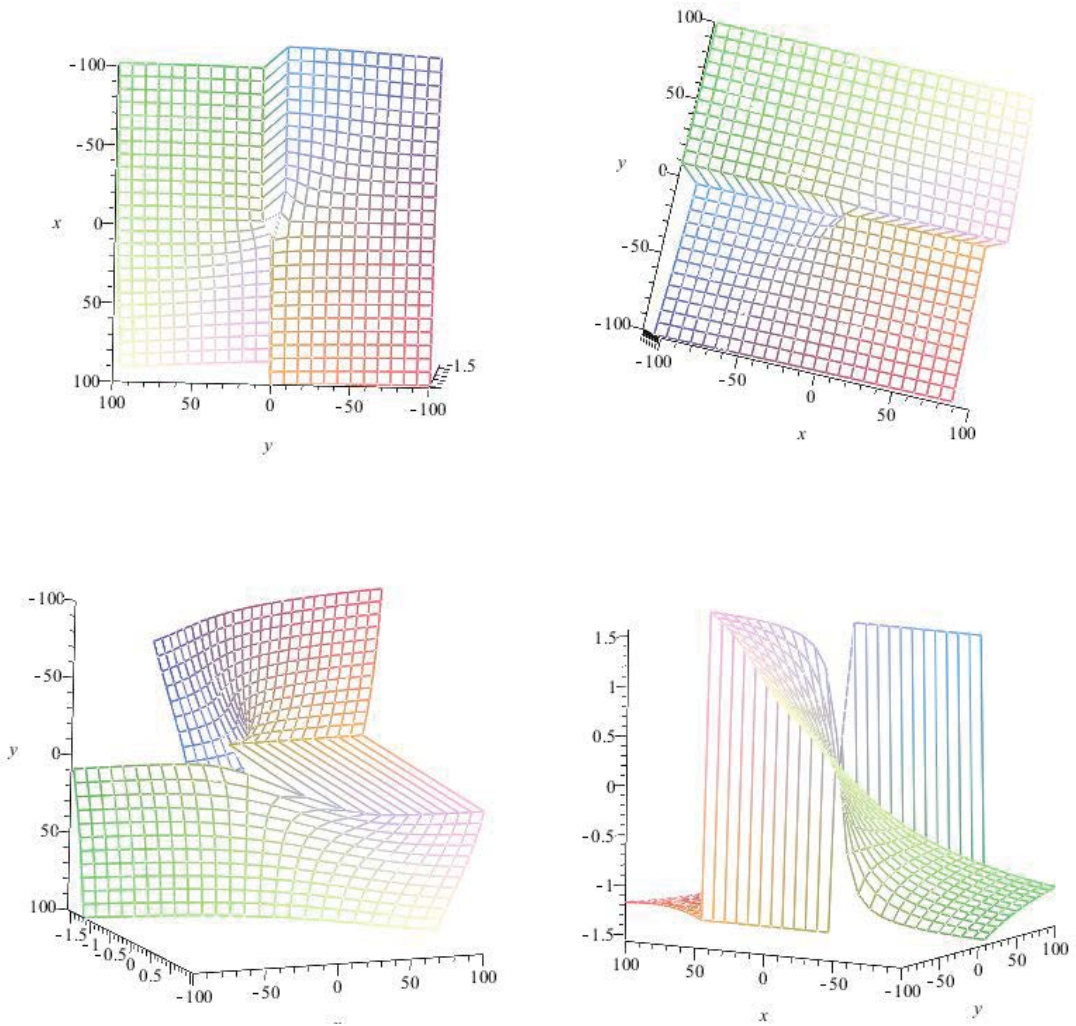

Figure 9: The direction graphic presentation. 


\section{Rectangle}

We will begin by applying the general sinus and Co sinus in a rectangle. We consider a rectangle $\mathrm{A}_{1} \mathrm{~A}_{2} \mathrm{~A}_{3}$ and we will apply the general sinus and Co sinus in this rectangle, so we got these results (Figure 3 ).

$$
\begin{aligned}
& \mathrm{a}_{3}=\sin \left(\alpha_{1}, \alpha_{2}\right) \cdot \mathrm{a}_{1} \\
& \mathrm{a}_{3}=\frac{\sin \left(\alpha_{1}\right)}{\sin \left(\alpha_{1}+\alpha_{2}\right)} \cdot \mathrm{a}_{1}
\end{aligned}
$$

(11) (Following our notation)

\section{N.B following the law of sinus notation}

In this case we notice:

$\alpha_{2}=\frac{\pi}{2}-\alpha_{1}$

So the equation (7) becomes:

$\mathrm{a}_{3}=\frac{\sin \left(\alpha_{1}\right)}{\sin \left(\frac{\pi}{2}\right)} \cdot \mathrm{a}_{1}=\sin \left(\alpha_{1}\right) \cdot \mathrm{a}_{1}$

So, the same formula of the actual sinus.

We announce also:

$\mathrm{a}_{2}=\cos \left(\alpha_{1}, \alpha_{2}\right) \cdot \mathrm{a}_{1}$

\section{N.B following our notation}

$a_{2}=\frac{\sin \left(\alpha_{2}\right)}{\sin \left(\alpha_{1}+\alpha_{2}\right)} \cdot a_{1}$

So the equation (10) becomes $\left(\alpha_{2}=\frac{\pi}{2}-\alpha_{1}\right)$

$\mathrm{a}_{2}=\frac{\sin \left(\frac{\pi}{2}-\alpha_{1}\right)}{\sin \left(\frac{\pi}{2}\right)} \cdot \mathrm{a}_{1}=\cos \left(\alpha_{1}\right) \cdot \mathrm{a}_{1}$

So, the same formula of the actual Co sinus.

We will compare the general tangent with the actual form. We announce the general form:

$\tan \left(\alpha_{1}, \alpha_{2}\right)=\frac{\sin \left(\alpha_{1}\right)}{\sin \left(\alpha_{2}\right)}=\frac{\sin \left(\alpha_{1}\right)}{\cos \left(\alpha_{1}\right)}=\tan \left(\alpha_{1}\right)$

So, the same formula of the actual tangent.

The derivative as a function. We will compare the derive function. Derive function of the general form:

$$
\begin{aligned}
& \frac{\mathrm{d} \sin (\mathrm{x}, \mathrm{y})}{\mathrm{dxy}}=\frac{\cos (\mathrm{x}, \mathrm{y})}{\sin (\mathrm{x}, \mathrm{y})} \mathrm{dx}-\sin (\mathrm{x}, \mathrm{y}) \operatorname{cotan}(\mathrm{x}+\mathrm{y}) \mathrm{dy} \\
& \frac{\mathrm{d} \cos (\mathrm{x}, \mathrm{y})}{\mathrm{dxy}}=-\cos (\mathrm{x}, \mathrm{y}) \operatorname{cotan}(\mathrm{x}+\mathrm{y}) \mathrm{dx}+\frac{\sin (\mathrm{x}, \mathrm{y})}{\sin (\mathrm{x}+\mathrm{y})} \mathrm{dy} \\
& \text { If } \mathrm{y}+\mathrm{x}=\frac{\pi}{2} \\
& \text { (the link of the general form and actual form), we get: } \\
& \frac{\mathrm{d} \sin (\mathrm{x})}{\mathrm{dx}}=\cos (\mathrm{x}) \\
& \frac{\mathrm{d} \cos (\mathrm{x})}{\mathrm{dx}}=-\sin (\mathrm{x})
\end{aligned}
$$

So, the same formula of the actual Sinus and Co sinus.

\section{The table of usual angles and the value's circle}

We will compare the value's table of the usual angles between actual form and general form of the trigonometrically function (Table 1).

$\alpha_{1}$ Represent the studied angle (the line) $\alpha_{2}$ represent the projection angle (the colonel).

We notice if we have $\alpha_{1}+\alpha_{2}=\pi / 2$. We will get the same table of the actual sinus.

If we have $\alpha_{1}+\alpha_{2}=\pi / 2$, the Sinus axe is a vertical (Figure 5).

So this we notice the same configuration of actual form.

\section{Remark 3}

So, fallowing the previous discussion we can notice the formula in the theorem (1) is the general Sinus, also they formula in the theorem (2) is the general Trigonometrical Function.

\section{General formula in n-gon}

In this part we are going to discuss the general trigonometrically function in n-gon, based on:

1. The notion constructability to polygons to discuss and justify the amount of data (that was announced in the abstract) which we think is minimal and reasonable. Based on small hypotheses: the amount of data is minimal and reason- able if it is sufficient to form a unique polygon. (See detail in paragraph: Is there any Formula more general than this one?)

2. The result of the previous part (General trigonometrically function).

3. Decomposition a polygon in (n-2) triangle.

The formula is denied by parameters that we must be present as data: $\mathrm{n}-2$ successive segments and $\mathrm{n}$ angles (In fact we need just $\mathrm{n}-1$ angles, but, according to Euclid's formula, the lack of data is not important).

\section{Definition 2}

Notation and terminology: To simplify and explain this formula, we add new symbols and concepts:

Let's $\pi$ a plane, we have $n$ points named $A_{1}, A_{2}, A_{3} \ldots A_{n}$.

When we join those points, we must follow this order: $A_{i} \rightarrow A_{i+1}$ as a result we will get the polygon of $n$-segment (Figure 10).

Sinus side a: The Sinus side is the segment in polygon, the sinus side is $a_{n}$. In case the triangle, sinus side is $a_{3}$. So we notice if we consider the angle $a_{3}$ is the studies angle, the segment $a_{3}$ is Sinus side in actual sinus.

Adjunct side: The Adjection side is the segment in polygon; the adjunct side is $a_{n-1}$. In case the triangle, sinus side $a_{2}$ So we notice if we considered the angle $\mathrm{a}_{3}$ is the studie angle, the segment $\mathrm{a}_{2}$ is adjunct side in actual co sinus.

Sous sinus side: In a polygon $\pi$ plane, if we joined the $A_{1}$ point to (n-1) points (to every other point), except two segments $\overline{A_{1} A_{2}}$ and $\overline{A_{n} A_{1}}$, we will get ( $n-3)$ sous sinus side, also we decompose this polygon in (n-3) triangles, where a sous sinus side becomes a sinus side in triangle.

We note $\operatorname{scsin}_{\mathrm{i}}$ (sous side sinus in Latin linguistic: Sous costula sinus). 


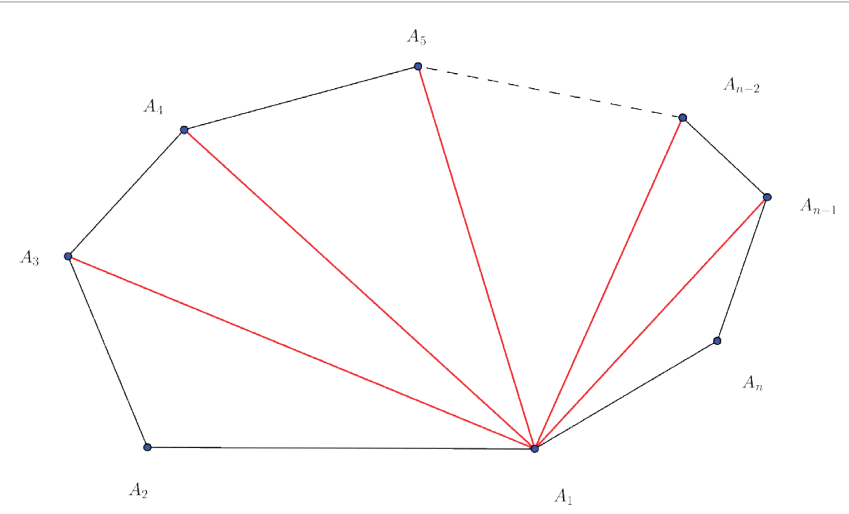

Figure 10: n-gon presentation.

$$
\operatorname{sc} \sin _{i}=\overline{A_{1} A_{i+2}}, i \in(0,1,2,3 \ldots \mathrm{n})
$$

\section{Remark 4}

If $\mathrm{i}=0, \operatorname{scsin}_{0}=\overline{\mathrm{A}_{1} \mathrm{~A}_{2}}$, we notice $\operatorname{scsin}_{0}$ becomes a polygon segment. And if $i=n-2, \operatorname{sesin}_{n-2}=\overline{A_{1} A_{n}}$

we notice $\operatorname{SCSin}_{\mathrm{n}-2}$ becomes a sinus side.

\section{Direction angle}

We will take angles defined by $A_{2} A_{1} A_{n}$. If we divide the polygon in the point $A_{1}$, this angle will be also divided and the partial angles will be the angle of projection in every triangle. This angle is noted as direct and defined by $\left(\mathrm{A}_{2+\mathrm{i}} \mathrm{A}_{1} \mathrm{~A}_{3+\mathrm{i}}\right), i \in(0,1,2,3 \ldots \mathrm{n})$

So direct $t_{\mathrm{i}}=\left(\mathrm{A}_{1+\mathrm{i}} \mathrm{A}_{1} \mathrm{~A}_{2+\mathrm{i}}\right)$

\section{Remark 5}

If $\mathrm{i}=1$, direct ${ }_{0}=\left(\mathrm{A}_{2} \mathrm{~A}_{1} \mathrm{~A}_{3}\right)$

- Complementary direction angle: Codirect: $_{i}$ represent the complementary of the direction angle the other $i$.

- Accumulation Direction angle: Accudirct: represent the accumulation of the direction angle other $i$.

\section{Theorem 4}

The general theorem in n-gon: We consider a n-gon, must know $(\mathrm{n}-1)$ segment and $\mathrm{n}$ angles. We can calculate two segment sinus side and ajection said and n-3 (all) sous side sinus, also (n-3) (all) direction angles (Figure 10).

$$
\begin{aligned}
& a_{n}=\sin \left(\operatorname{co}-\operatorname{direct}_{n-2}, \operatorname{accu}-\operatorname{direct}_{n-2}\right) \cdot \operatorname{scsin}_{n-3} \\
& a_{n-1}=\cos \left(\operatorname{co}-\operatorname{direct}_{n-2}, a c c u-\operatorname{direct}_{n-2}\right) \cdot \operatorname{scsin}_{n-3} \\
& \operatorname{scsin}_{i}=\sin \left(\operatorname{co}-\operatorname{direct}_{i}, \operatorname{direct}_{i}\right) \\
& \operatorname{dirct}_{i}=\operatorname{directio}\left(a_{i+1}, \operatorname{scsin}_{i-1}, \operatorname{co}-\operatorname{direct}_{i}\right) \\
& \operatorname{accu}-\operatorname{direct}_{\mathrm{i}}=\alpha_{\mathrm{n}}-\sum_{\mathrm{j}=1}^{\mathrm{i}-1} \operatorname{dirct}_{\mathrm{j}} \\
& \operatorname{co}-\operatorname{direct}_{\mathrm{i}}=\sum_{\mathrm{j}}^{\mathrm{i}} \alpha_{\mathrm{j}}+\sum_{\mathrm{p}=1}^{\mathrm{i}-1} \operatorname{direct}_{\mathrm{p}}-(\mathrm{i}-1) \pi
\end{aligned}
$$

\section{Remark 6}

This formula can be used in all forms of polygons, due to its independent of the polygons nature. However, the difference is that a general method of application does not exist. So, the user chose the appropriate parameters.

\section{Is there any formula more general than this one?}

We think that the result we had is the most general in Euclidean geometry because any unreasonable decrease in the amount of data will lead to infinity of possible studied objects.

Our thesis is based on simple and traditional fundamentals depending on efficiency and we are aware that this concept 'efficiency' is used only on applied sciences and by that we suggest this concept (efficiency) in Mathematics to evaluate and discuss theories.

According to this concept we can evaluate a mathematical theories and formulas by discussing the amount of results and compare it to the amount of data. We mean by results, the properties of the studied objects, so the maximum result we can find is to find all the object's intrinsic properties, this mean that the number of results is limited and we can't improve the efficiency of our Formula unless we try to reduce the amount of data which is the case in our theory.

Our formula is based on the study of a simple triangle, so to explain that the formula can use the minimal and reasonable amount of data we will come back to the triangle (Figure 11).

Let's suppose to have two points $A_{1}$ and $A_{2}$ of a plane (if we define the position of $A_{1}$ and $A_{2}$ we will fix a segment $A_{1} A_{2}$ ) if we want to form a unique triangle using this amount of data $A_{1} A_{2}$

we will find an infinity of intersections (the point $\mathrm{A}_{3}$ ) of the lines passing through $A_{1}$ and others passing through $A_{2}$ (in one single point passes an infinity of lines) where the triangle $\mathrm{A}_{1} \mathrm{~A}_{2} \mathrm{~A}_{3}$ is formed.

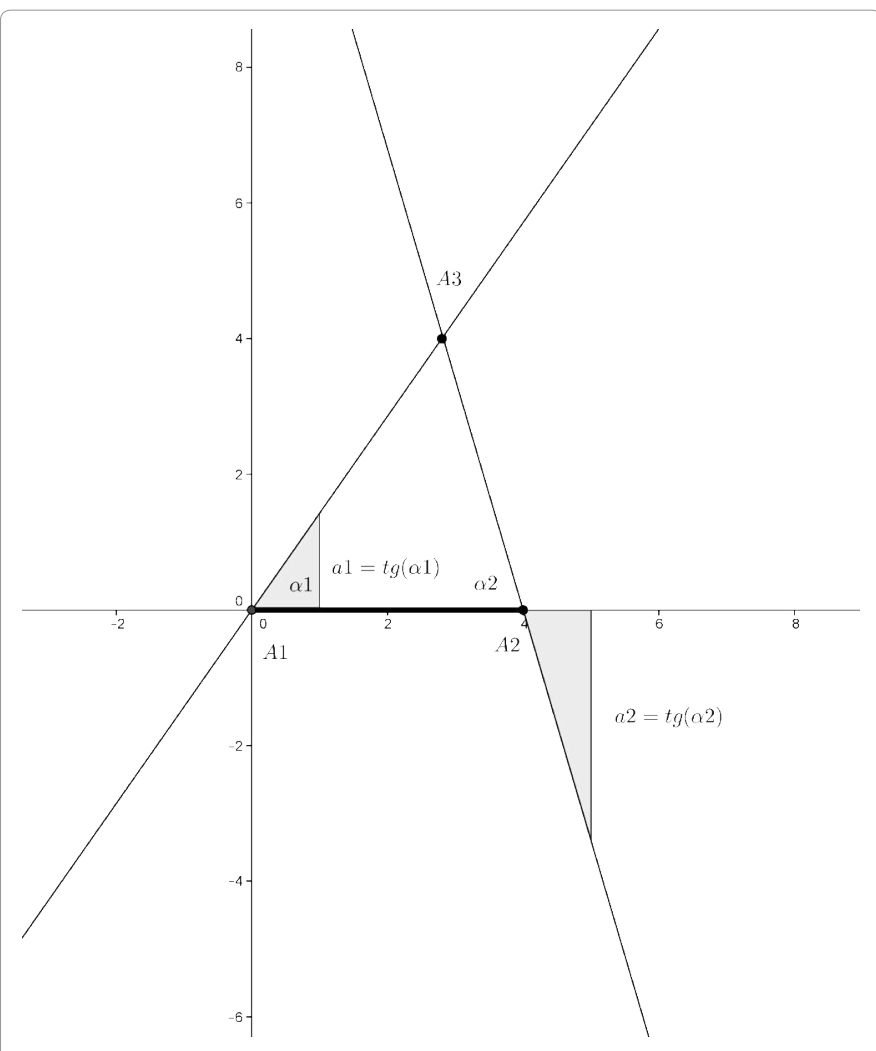

Figure 11: The unicité of point presentation. 
In order to form a unique triangle we must fixe the position of the point $A_{3}$, so that mean we should fix the angle $A_{3} A_{1} A_{2}\left(\alpha_{1}\right)$ and $A_{1} A_{2} A_{3}$ $\left(\alpha_{2}\right)$. After fixing the segment $\overline{\mathrm{A}_{1} \mathrm{~A}_{2}}$

the only parameter that can influence the position of the point $\mathrm{A}_{3}$ is the angle, so the minimal and reasonable amount of data is the segment ' $\overline{\mathrm{A}_{1} \mathrm{~A}_{2}}$ ' and the two angles $A_{3} A_{1} A_{2}\left(\alpha_{1}\right)$ and $A_{1} A_{2} A_{3}\left(\alpha_{2}\right)$.

The unicity of the triangle is proven by the next proof:

Let's: $y_{1}=a_{1} \cdot x_{3}+b_{1}$ Cartesian equation of the adroit passing in $A_{1}\left(x_{1}+b_{1}\right)$ and $y_{2}=a_{2} \cdot x_{2}+b_{2}$ Cartesian equation of the adroit passing in $\mathrm{A}_{2}\left(\mathrm{x}_{2}, \mathrm{y}_{2}\right)$.

So $A_{3}\left(x_{3}, y_{3}\right)$ verify this system

$\mathrm{y}_{3}=\mathrm{a}_{1} \cdot \mathrm{x}_{3}+\mathrm{b}_{1}$ and $\mathrm{y}_{3}=\mathrm{a}_{2} \cdot \mathrm{x}_{3}+\mathrm{b}_{2}$

According to equation (27) we find:

$a_{1} \cdot x_{3}+b_{1}=a_{2} \cdot x_{3}+b_{2}$

So,

$$
\mathrm{x}_{3}=\frac{\mathrm{b}_{2}-\mathrm{b}_{1}}{\mathrm{a}_{1}-\mathrm{a}_{2}} ; \mathrm{a}=\frac{\Delta \mathrm{Y}}{\Delta \mathrm{X}}=\mp \tan \alpha
$$

\section{Remark 7}

In Equation (30) you are going to notice that $\mathrm{a}_{1}$ and $\mathrm{a}_{2}$ must be under a condition: $\mathrm{a} 1-\mathrm{a} 2 \neq 0$.

Based on Equation (33), $\tan \alpha_{1}-\tan \alpha_{1} \neq 0$, so $\alpha_{1}$ and $\alpha_{1}$ are conditioned, that means our first statement is the Abstract concerning $n$-gon nature was wrong. In fact this condition does not make our statement false because it is necessary to form a triangle.

It mean a depend on $\alpha$ so $\mathrm{x}_{3}$ depend que $\alpha$ because $\mathrm{b}$ just constant.

Finlay position of point $\mathrm{A}_{3}\left(\mathrm{x}_{3} \mathrm{y}_{3}\right)$ depend on $\alpha_{1}, \alpha_{2}$ and $\overline{\mathrm{A}_{1} \mathrm{~A}_{2}}$.

In the quadrilateral we need to fixe three points (fixing two segments. In order to form the quadrilateral we must fixe the position of the fourth point (fixing the angles: the ones who define the proportionality factor).

As for the Pentagon we need to fixe four points (fixing three segments). In order to form the Pentagon we must fixe the position of the fifth point (fixing the angles: the ones who define the proportionality factor).

Following the exact same logic, in the n-gon we notice the need to fixe "n-1" points (fixing (n-2)) segments), in order to form the n-gon we must fixe the position of the last point.

Using the Mathematical induction we can prove that the minimal and reasonable amount of data is in function of " $n$ " (n: number of segments and number of angles) and are expressed by this formula:

(n-1) angles and (n-2) segments.

\section{Proof 2}

In this proof, will be based on the theorem (2) and theorem (3). To generalize this results and applies it in the polygon, we will work in this plan:

We will apply theorem (2) and theorem (3) in a quadrilateral, a pentagon and a Hexagon.

2. After noticing the results of the previous forms we can use the mathematical induction to write the all formula

So we will begin by:
Quadrilateral: We consider a quadrilateral $\mathrm{A}_{1} \mathrm{~A}_{2} \mathrm{~A}_{3} \mathrm{~A}_{4}$ (Figure 12).

In triangle $\mathrm{A}_{2} \mathrm{~A}_{1} \mathrm{~A}_{3}$

$\left(\widehat{\mathrm{A}_{2} \mathrm{~A}_{1} \mathrm{~A}_{3}}\right)=\operatorname{direct}_{1}=\operatorname{directio}\left(\mathrm{a}_{2} \mathrm{a}_{1} \alpha_{1}\right)$

Where $\mathrm{a}_{1}=\overline{\mathrm{A}_{1} \mathrm{~A}_{2}}=\operatorname{scsin}_{0}$ and $\alpha_{1}=$ coderict $_{1}$

So $\left(\widehat{\mathrm{A}_{2} \mathrm{~A}_{1} \mathrm{~A}_{3}}\right)$

$=\operatorname{direct}_{1}=\operatorname{directio}\left(\mathrm{a}_{2} \mathrm{a}_{1} \mathrm{a}_{1}\right)=\operatorname{directio}\left(\mathrm{a}_{2}, \operatorname{scsin}_{0}\right.$, codirect $\left._{1}\right)$

Finally

$\overline{\mathrm{A}_{1} \mathrm{~A}_{3}}=\operatorname{scsin}{ }_{1}=\sin \left(\alpha_{1}\right.$, direct $\left._{1}\right) \cdot \mathrm{a}_{1}$

In triangle $\mathrm{A}_{3} \mathrm{~A}_{1} \mathrm{~A}_{4}$

$a_{4}=\overline{A_{1} A_{4}}=\sin \left(\left(\widehat{A_{1} A_{3} A_{4}}\right),\left(\widehat{A_{3} A_{1} A_{4}}\right) \cdot \overline{A_{1} A_{3}}\right.$

$\left(\widehat{A_{1} A_{3} A_{4}}\right)=\left(\widehat{A_{2} A_{3} A_{4}}\right)-\left(\widehat{A_{2} A_{3} A_{1}}\right)$

$\left(\widehat{\mathrm{A}_{2} \mathrm{~A}_{3} \mathrm{~A}_{4}}\right)=\alpha_{2},\left(\widehat{\mathrm{A}_{2} \mathrm{~A}_{3} \mathrm{~A}_{1}}\right)=\pi-\alpha_{1}-\left(\left(\widehat{\mathrm{A}_{2} \mathrm{~A}_{3} \mathrm{~A}_{1}}\right)=\operatorname{direct}_{1}\right)$

$\left(\widehat{\mathrm{A}_{3} \mathrm{~A}_{1} \mathrm{~A}_{4}}\right)=\left(\widehat{\mathrm{A}_{2} \mathrm{~A}_{1} \mathrm{~A}_{4}}\right)-\left(\widehat{\mathrm{A}_{2} \mathrm{~A}_{1} \mathrm{~A}_{3}}\right)$

$\left(\widehat{\mathrm{A}_{2} \mathrm{~A}_{1} \mathrm{~A}_{4}}\right)=\alpha_{4},\left(\widehat{\mathrm{A}_{2} \mathrm{~A}_{1} \mathrm{~A}_{3}}\right)=\left(\left(\widehat{\mathrm{A}_{2} \mathrm{~A}_{3} \mathrm{~A}_{1}}\right)=\operatorname{dirct}_{1}\right)$ And $\overline{\mathrm{A}_{1} \mathrm{~A}_{4}}=\operatorname{scsin}_{1}$

So we get:

$\mathrm{a}_{4}=\overline{\mathrm{A}_{1} \mathrm{~A}_{4}}=\sin \left(\alpha_{2}+\alpha_{2}+\operatorname{direct}_{1}-\pi, \alpha_{4}-\right.$ direct $\left._{1}\right) \cdot \operatorname{scsin}_{1}$

$\mathrm{a}_{3}=\overline{\mathrm{A}_{1} \mathrm{~A}_{4}}=\cos \left(\alpha_{2}+\alpha_{2}+\operatorname{direct}_{1}-\pi, \alpha_{4}-\right.$ direct $\left._{1}\right) \cdot \operatorname{scsin}_{1}$

Where codirect ${ }_{2}=\alpha_{1}+\alpha_{2}+$ direct $_{1}-\pi$ and accudirect ${ }_{2}=\alpha_{4}+$ dirct $_{1}$ codirect $_{2}=\alpha_{1}+\alpha_{2}+$ direct $_{1}-\pi$ and accudirect ${ }_{2}=\alpha_{4}+$ dirct $_{1}$

So

$\mathrm{a}_{4}=\overline{\mathrm{A}_{1} \mathrm{~A}_{4}}=\operatorname{din}\left(\right.$ codirect $_{2}$, accudirect $\left._{2}\right) \cdot \operatorname{scsin} 1$

$\mathrm{a}_{3}=\overline{\mathrm{A}_{3} \mathrm{~A}_{4}}=\operatorname{din}\left(\right.$ codirect $_{2}$, accudirect $\left.{ }_{2}\right) \cdot \operatorname{scsin} 1$

Pentagon: We notice that the equations (32) and (33) (triangle $\left.A_{2} A_{1} A_{4}\right)$ are the same in a Pentagon, the rest of the proof is based on the previous equations (32) and (33).

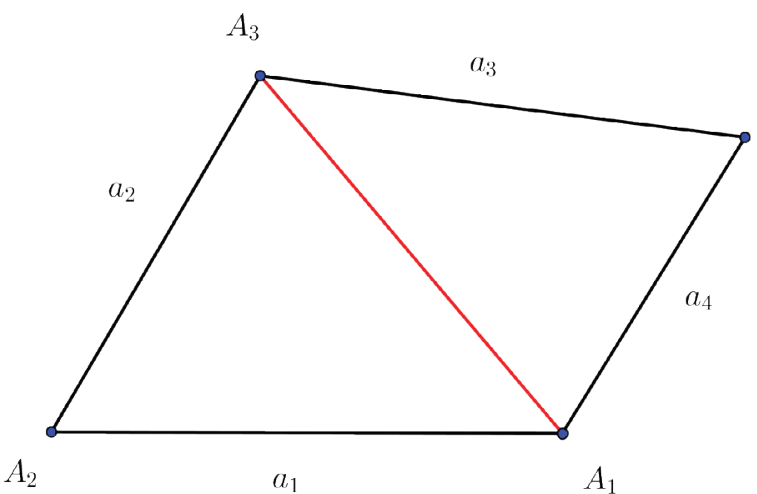

$A_{4}$

Figure 12: The quadrilateral presentation. 


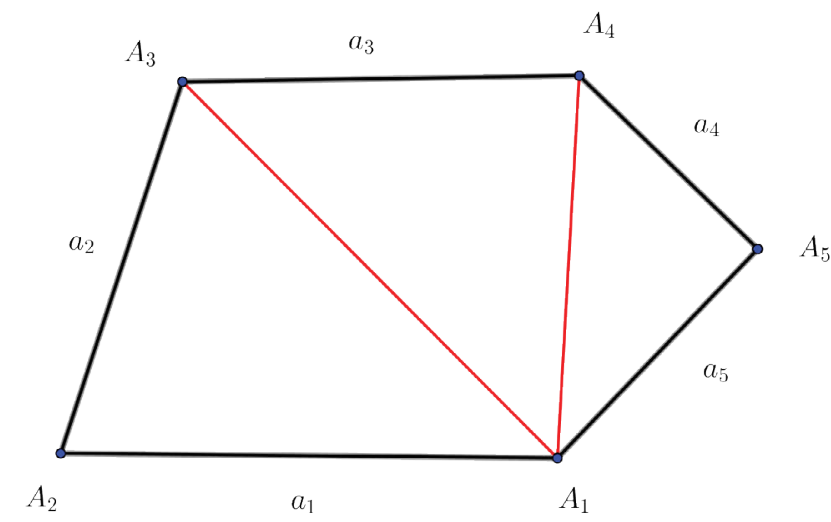

Figure 13: The pentagon presentation.

We will find (Figure 13):

In triangle $\mathrm{A}_{3} \mathrm{~A}_{1} \mathrm{~A}_{4}$

$\left(\widehat{A_{3} A_{1} A_{4}}\right)=\operatorname{direct}_{2}=\operatorname{directio}\left(a_{3}, \operatorname{scsin}_{1}\right.$, codirect $\left._{2}\right)$

$\overline{\mathrm{A}_{1} \mathrm{~A}_{4}}=\operatorname{scsin}_{2}=\sin \left(\right.$ codirectio $_{2}$, direct $\left._{2}\right) \cdot \operatorname{scsin}_{1}$

In triangle $\mathrm{A}_{3} \mathrm{~A}_{1} \mathrm{~A}_{4}$

$\mathrm{a}_{5}=\overline{\mathrm{A}_{1} \mathrm{~A}_{4}}=\sin \left(\left(\widehat{\mathrm{A}_{1} \mathrm{~A}_{4} \mathrm{~A}_{5}}\right),\left(\widehat{\mathrm{A}_{4} \mathrm{~A}_{1} \mathrm{~A}_{5}}\right)\right) \cdot \overline{\mathrm{A}_{1} \mathrm{~A}_{4}}$

Where:

$\left(\widehat{\mathrm{A}_{1} \mathrm{~A}_{4} \mathrm{~A}_{5}}\right)=\alpha_{1}+\alpha_{2}+\alpha_{3}+\operatorname{direct}_{1}+\operatorname{direct}_{2}-2 \pi=$ codirect $_{3}$

$\left(\widehat{\mathrm{A}_{4} \mathrm{~A}_{1} \mathrm{~A}_{5}}\right)=\alpha_{5}-$ direct $_{1}-$ direct $_{2}=$ accudirect $_{3}$

So:

$\mathrm{a}_{5}=\sin \left(\right.$ codirect $_{3}$, accudirect $\left._{3}\right) \cdot \operatorname{scsin}_{2}$

$\mathrm{a}_{4}=\cos \left(\right.$ codirect $_{3}$, accudirect $\left.{ }_{3}\right) \cdot \operatorname{scsin}_{2}$

Hexagon: We notice that the equations (32), (33), (37) and (38) (triangle $\mathrm{A}_{2} \mathrm{~A}_{1} \mathrm{~A}_{3}$ and triangle $\mathrm{A}_{3} \mathrm{~A}_{1} \mathrm{~A}_{4}$ ) are the same in a Hexagon, the rest of the proof is based on the previous equations (Figure 14).

In triangle $\mathrm{A}_{4} \mathrm{~A}_{1} \mathrm{~A}_{1}$

$\left(\widehat{\mathrm{A}_{4} \mathrm{~A}_{1} \mathrm{~A}_{5}}\right)=\operatorname{direct}_{3}=\operatorname{directio}\left(\mathrm{a}_{4}, \operatorname{scsin}_{2}, \operatorname{codirect}_{3}\right)$

$\overline{\mathrm{A}_{1} \mathrm{~A}_{5}}=\operatorname{scsin}{ }_{3}=\sin \left(\operatorname{codirect}_{3}, \operatorname{direct}_{3}\right) \cdot \operatorname{scsin}_{2}$

In triangle $\mathrm{A}_{5} \mathrm{~A}_{1} \mathrm{~A}_{6}$

$a_{6}=\overline{A_{1} A_{6}}=\sin \left(\left(\widehat{A_{1} A_{5} A_{6}}\right), \overline{\left(A_{5} A_{1} A_{6}\right)}\right) \cdot \overline{A_{1} A_{5}}$

Where:

$\left(\widehat{\mathrm{A}_{1} \mathrm{~A}_{5} \mathrm{~A}_{6}}\right)=\alpha_{1}+\alpha_{2}+\alpha_{3}+\alpha_{4}+$ direct $_{1}+$ direct $_{2}+$ direct $_{3}-3 \pi=$ codirect $_{4}$ And

$\left(\widehat{\mathrm{A}_{5} \mathrm{~A}_{1} \mathrm{~A}_{6}}\right)=\alpha_{6}-$ direct $_{1}-$ direct $_{2}-$ direct $_{3}=$ accudirect $_{4}$

So: $\mathrm{a}_{6}=\sin \left(\right.$ codirect $_{4}$, accudirect $\left.{ }_{4}\right) \cdot \operatorname{scsin}_{3}$

$\mathrm{a}_{6}=\sin \left(\right.$ codirect $_{4}$, accudirect $\left._{4}\right) \cdot \operatorname{scsin}_{3}$

$\mathrm{a}_{5}=\cos \left(\right.$ codirect $_{4}$, accudirect $\left._{4}\right) \cdot \operatorname{scsin}_{3}$

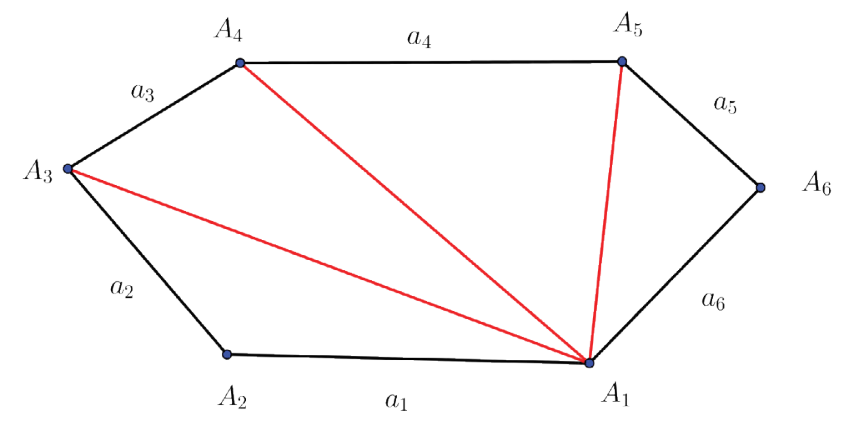

Figure 14: The hexagon presentation.

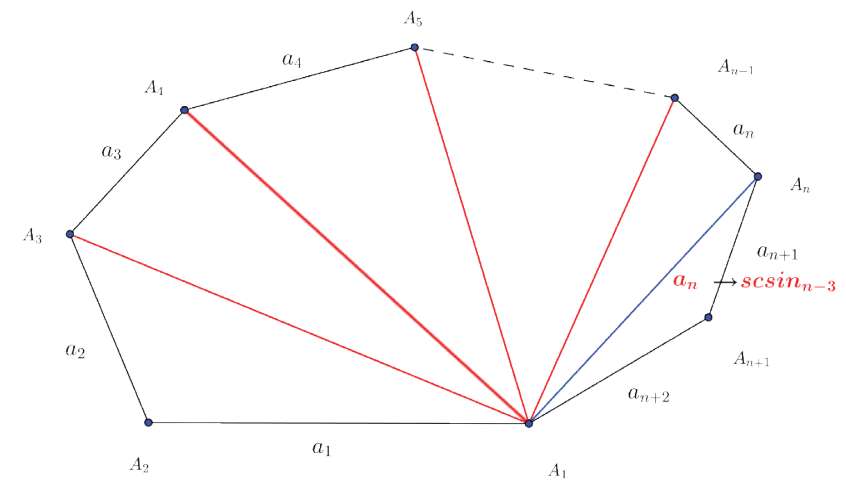

Figure 15: The mathematic induction png presentation.

\section{Remark 8}

After noticing that if we write the final results (in function of $\mathrm{n}$ ), we find the same results in (quadrilateral, pentagon and hexagon). We conclude that this formula follows a logical law, so we will use mathematical induction to confirm the generality of the formula.

\section{Mathematical induction}

We suppose that the equation (21) is true and we will prove that:

$a_{n+2}=\sin \left(\right.$ codirect $\left._{n} ; \operatorname{accudirect}_{n}\right) \cdot \operatorname{scsin}_{n-1}$

If we add a point in plane, two segments will be added to the polygon (forming by $\mathrm{n}$ points). ' $\mathrm{a}_{\mathrm{n}}$ ' Will be now an interior segment in the new polygon (forming by $n+1$ points), so $a_{n}=\operatorname{scsin}_{n-3}$ (Figure 15).

We notice that:

Direct $_{2}$ And $\operatorname{scin}_{2}$ are the same.

In ( $\mathrm{n}=4$, quadrilateral) direct ${ }_{2}$, direct ${ }_{3}$ and $\operatorname{scin}_{2}, \operatorname{scin}_{3}$ are the same.

Generally, the term $\operatorname{scin}_{i}$ and direct $_{i}=i \in(1,2,3 \ldots . n)$ remain the same, so what makes $a_{n+2}$ special is co-direct ${ }_{n}$ and accu-direct $t_{n}$ and if we apply (21), we will find a (47) and according to principle of math induction, we conclude that the formula is correct and generalized.

\section{Conclusion}

We tried in this paper to discuss the generalized trigonometrical function and all the properties of an object based on the amount of data 
we have (we think it's the reasonable and minimal amount of data). To open the door of discussion we will propose a series of problematic in order to exploit the maximum from these results.

1. We think if we generalized the trigonometrical function, we will get much more opportunity to evaluate it in many fields of science, for example we think that these results might be a solution to the problem of the retaliatory signals. We think also that our results can improve the kinetical study in the mechanics field, and we think may be evaluating the rayonement study.

2. Can we improve the general law of Sinus to find the same results while studying an object in the space based on a new minimal amount of data?

\section{References}

1. Eli M (1998) Trigonometric delights. Princeton University Press.

2. Boyer (1991) A history of mathematics, p: 252

3. Boyer (1991) Greek trigonometry and mensuration, pp: 158-159.

4. Boyer (1991) A history of mathematics, p: 210

5. Trigonometry (2008). Encyclopedia Britannica.

6. Dabashi H (1996) Khwajah Nasir al-Din Tusi: Routledge history of world philosophies. In: Nasr SH, Leaman O (Eds), History of Islamic Philosophy. London: Routledge, p: 529

7. Lewis JR (2003) The astrology book: The encyclopedia of heavenly influences Visible Ink Press, p: 574.
8. Grisard J (1968) Francois Viete mathematicien de la fin du seizieme siecle, Thesa de 3eme cycle: Ecole pratique des hautes etudes, Paris.

9. Sesiano J (2000) Islamic mathematics. In: Selin, Helaine, Ambrosio D, Ubiratan (Eds), Mathematics across cultures: The history of non-western mathematics. Springer.

10. Russell RA (2011) Generalized law of sines. Wolfram Mathworld.

11. Archibald RC (1916) The history of the construction of the regular polygon of seventeen sides. Bull Amer Math Soc 22: 239-246.

12. Hall T (1970) Carl friedrich gauss: A biography. MIT press.

13. Gauss CF (1965) Disquisitiones arithmeticae. Leipzig: Fleischer, 1801. Translated from Latin by Clarke AA, Yale University Press.

14. Wantzel PL (1837) Journal de mathematiques pures et appliquees, pp: 2366 2372.

15. Keller W (1983) Factors of Fermat numbers and large primes of the formk. $2^{n}+$ 1. Math Comp 41: 661-673.

16. Young J, Buell DA (1988) The twentieth fermat number is composite. Amer Math Soc 50: 261-263.

17. Archibald RC (1920) Gauss and the regular polygon of seventeen sides. Amer Math Monthly 27: 323-326.

18. Roark RJ (1954) Formulas for stress and strain. (3rd Edn), New York. McGrawHill.

19. Court A (1925) College geometry, a second course in plane geometry for colleges and normal schools. 70-71.

20. Coxeter HSM, Greitzer SL (1967) Ptolemy's theorem and its extensions: In geometry revisited. Washington DC, USA. Math Assoc Amer, pp: 42-43.

21. English, Latin dictionary: Glossarium anglico-latinum. 